\title{
Synthesis and Characterization of Ni-Mo Filler Brazing Alloy for Mo-W Joining for Microwave Tube Technology
}

\author{
Frank Ferrer Sene ${ }^{a *}$, Cláudio Costa Motta \\ ${ }^{a}$ Nuclear and Energy Research Institute - IPEN, Av. Professor Lineu Prestes, \\ 2468, CEP 05508-000, São Paulo, Brazil \\ ${ }^{\mathrm{b}}$ University of Sao Paulo - USP, São Paulo, Brazil
}

Received: January 30, 2012; Revised: August 19, 2012

\begin{abstract}
A brazing process based on Ni-Mo alloy was developed to join porous tungsten cathode bottom and dense molybdenum cathode body for microwave tubes manufacture. The Ni-Mo alloy was obtained by mixing and milling powders in the eutectic composition, and applied on the surface of the components. The brazing was made at $1400{ }^{\circ} \mathrm{C}$ by using induction heating in hydrogen for 5 minutes. Alumina surfaces were coated with the binder and analyzed by Energy Dispersive X-rays Fluorescence. The brazed samples were analyzed by Scanning Electron Microscopy coupled to Energy Dispersive Spectroscopy. Stress-strain tests were performed to determine the mechanical behavior of the joining. The quality of the brazing was evaluated by assuring the presence of a "meniscus" formed by the Ni-Mo alloy on the border of the tungsten and molybdenum joint, the absence of microstructural defects in the interface between the tungsten and molybdenum alloys, and the adhesion of the brazed components.
\end{abstract}

Keywords: high temperature brazing, induction heating, powder metallurgy, decopperization, interface

\section{Introduction}

Several different areas of Science and Technology are involved in the development of microwave tubes. When thermionic cathodes, which are fundamental components in microwave tube devices are exposed to heat, they become sources of free electrons which will be further accelerated in an electron gun forming a dense electron beam. These electrons might have their velocity modulated, decelerated, and consequently they will emit electromagnetic radiation in the range of microwave ${ }^{1}$. It is necessary to join components by brazing during the development of thermionic cathodes, however, there is a challenge concerning the choice of the appropriate material to be used as a filler. Brazing is a thermal activated process usually used to join components, and it is done by the addition of a melted filler material or brazing alloy. When the filler is in the liquid state, it wets the surface of the parts to be joined, and after cooling, the components are bonded together ${ }^{2,3}$.

In the present work, the brazing alloy must wet both tungsten and molybdenum (parts of the cathode), and the brazing temperature must be above the cathode working temperature $\left(1200^{\circ} \mathrm{C}\right)^{4}$, without causing any structural damage to the cathode components. Thermal shock followed by crack propagation, re-melting of the filler material, and contamination from other parts of the tube are other issues to be considered.

The Ni-Mo system is an alternative filler material ${ }^{5,6}$. The phase diagram of this system can be seen in Figure 1 and shows the eutectic composition (35.8 at.\% of molybdenum) at $1310^{\circ} \mathrm{C}^{[7]}$.

*e-mail: ffsene@ipen.br
The aim of the present work is to develop a brazing process which uses induction heating to join porous tungsten to dense molybdenum components, by using an eutectic composition of Ni-Mo alloy as a filler.

\section{Experimental}

\subsection{Powder homogenization and milling}

Nickel and molybdenum powders ( $99.9 \%$ purity) with nominal average particle size of $44 \mu \mathrm{m}$ were weighed, mixed, and ground using a ball mill. The amount of molybdenum (38.4 mol\%) was chosen based on the Ni-Mo phase diagram, and the grind was performed during 48 hours in anhydrous ethanol to minimize the oxidation reaction ${ }^{8,9}$.

\subsection{Binder preparation}

After the homogenization and milling, the powder was dried and selected to prepare a binder which would be further used as a coating on the surface of the cathode components (porous tungsten and dense molybdenum) ${ }^{3}$. The use of the binder was the way chosen to add the filler material into the components, and the binder preparation is shown schematically in Figure 2.

The binder was stirred using a glass rod for homogenization, and spread on the surface of an alumina plate using a brush; it was finally dried at $100{ }^{\circ} \mathrm{C}$. The composition of this layer was determined by EDX. 


\subsection{Brazing sample preparation}

Brazing was done in two different procedures: in the first procedure, the brazing was carried out to join only molybdenum components, and in the second arrangement, the brazing was carried out to join two different materials, such as a dense molybdenum and a porous tungsten, obtained from $\mathrm{W}-\mathrm{Cu}$ composite, previously decoppered at $1450{ }^{\circ} \mathrm{C}$, in hydrogen for 20 hours, using an induction furnace ${ }^{10}$.

Figure 3 presents the schematic diagram of the components to be brazed after the binder application done in four different ways to optimize the wetting stage, the capillary flow, and consequently to allow the final joining of two components.

In the first procedure a layer of binder was spread on the borders contact with both components, as shown in Figure 3a; the second procedure is similar to the first, however, the borders were coated with three layers following intervals of 5 minutes each. It was verified that the chosen

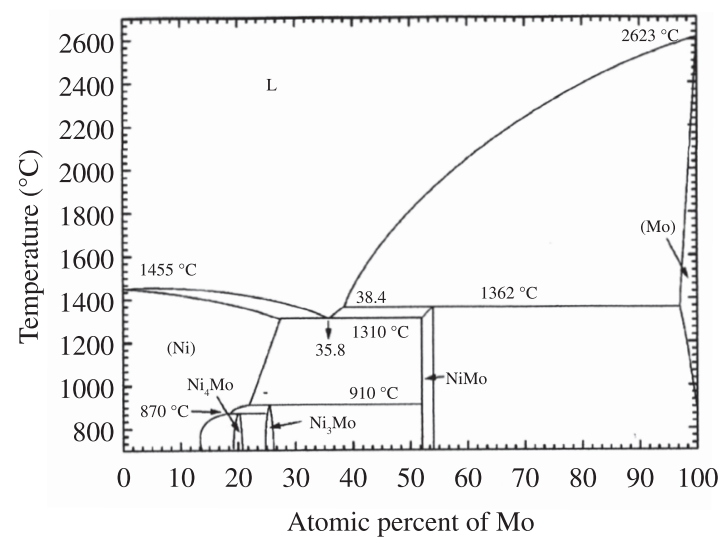

Figure 1. Phase diagram for high temperatures for Ni-Mo system? ${ }^{7}$.

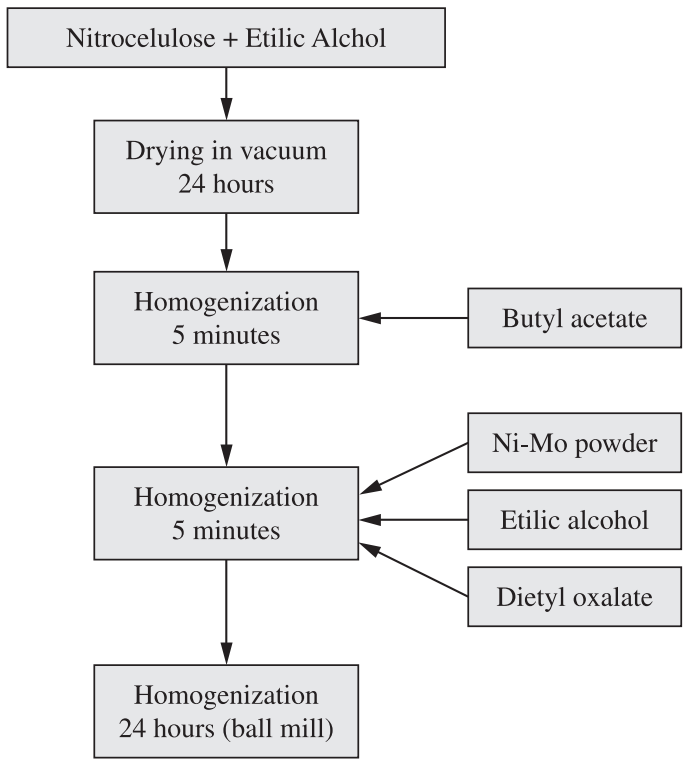

Figure 2. Flowchart for the binder preparing containing Ni and Mo. interval is suitable to dry the binder on the surface, without any damage to the previous coating. The third procedure consists on the application of the binder only on the surface in contact with both components, as shown in Figure 3b, and the fourth procedure is a combination of the second and the third ones.

\subsection{Brazing process}

The brazing process was done in a special heating chamber shown in Figure 4, assembled inside an induction heating system (Ambrel, model 3542). The flow of dry hydrogen keeps a reducing atmosphere, and the sample was held inside a graphite crucible which was self-heated by the absorption of electromagnetic waves in the radio-frequency range generated by the induction coil. The refractory heat
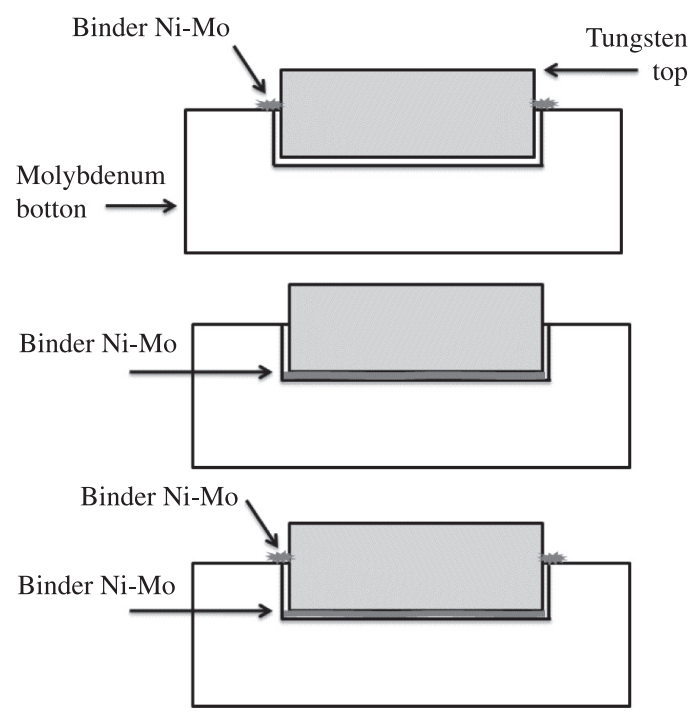

Figure 3. Schematic diagram for the binder application.

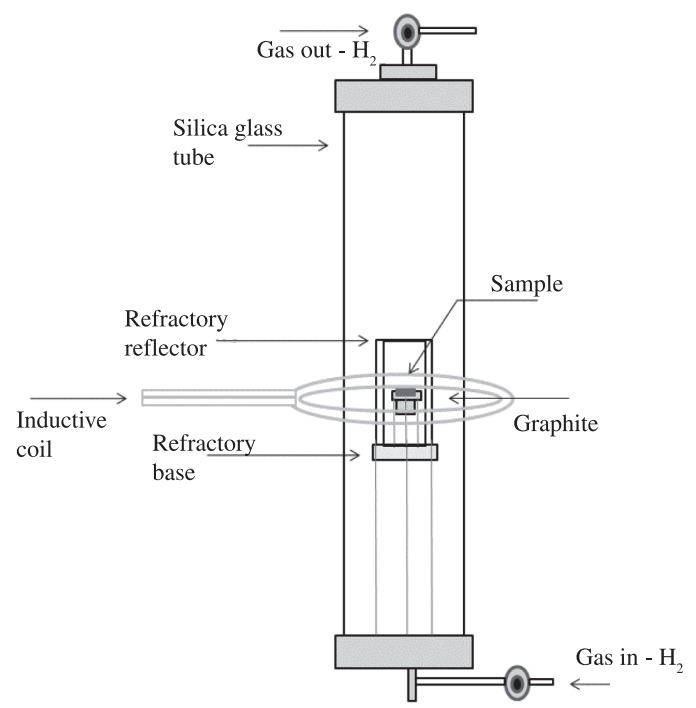

Figure 4. Heating device connected to the induction heating system applied to the brazing process in controlled atmosphere. 
shields reduce the thermal energy losses so heating can be achieved applying electrical currents ranging from 300 to 350 A. The dry hydrogen is controlled by two leak valves (Edwards LV-10K) located in the base and on the top of the heating device. The temperature of the sample was measured by an optical pyrometer (DFP2000) and it varied from 1330 to $1450{ }^{\circ} \mathrm{C}$.

\subsection{Structural and compositional analysis}

The composition of the Ni-Mo alloy and the homogeneity of the binder were determined by energy dispersive X-rays fluorescence spectroscopy (EDX) using an spectrometer Shimadzu, model EDX 720. The binder was spread on the surface of high purity alumina plates which was analyzed by selecting different spots of the surface. The same procedure was used to analyze tungsten surfaces previously coated with binder. These surfaces were analyzed prior and after the thermal treatment at the same temperature and atmosphere used for the brazing process.

$\mathrm{X}$-ray diffraction was performed to determine the phases present in the binder prior and after the heating treatment done to obtain the Ni-Mo alloy. These analyses, in addition to the powder size distribution determined by laser diffraction analysis (Cilas, model 1160) and SEM, are important techniques to characterize the mechanisms related to homogenization and milling.

\subsection{Microstructural analysis}

Scanning electron microscopy (SEM) (Jeol, model 6400) coupled to the energy dispersive spectroscopy (EDS) analysis (Thermoelectron), was used to determine the microstructure in the region of the brazing, including the interface between the components and the filler alloy, and mapping the amount of each element as a function of the position on the sample surface.

\subsection{Mechanical strength}

Similar samples prepared according to the arrangement presented in Figure 3 were used in the mechanical strength tests; an universal testing machine (Instron, model 1186) was used to determine the tensile strength value. These results were performed to verify the appropriate employment of the developed joints in microwave tube applications.

\section{Results and Discussion}

\subsection{Binder composition}

The nominal composition of the powder to be used as a filler is $35.8 \mathrm{Mo}-64.7 \mathrm{Ni}(\mathrm{mol} \%)$, and the real composition determined by EDX for ten samples coating the surface of alumina plates are shown in the Table 1 . The average standard deviation was $0,06 \mathrm{~mol} \%$ for each analyzed sample, and the analyzed surface area was $1 \mathrm{~cm}^{2}$. The binder for samples 1 to 5 were prepared using nitrocellulose with low kinematic viscosity (6 saybolt universal seconds) and the binder for samples 6 to 10 were prepared using nitrocellulose with high kinematic viscosity (360 saybolt universal seconds). It was observed that the composition of the samples 1 to 5 deviate from the nominal values due to the low viscosity of the binder, and consequently, the time sedimentation for $\mathrm{Ni}$ and Mo particles are different, increasing the concentration of $\mathrm{Ni}$ on the surface of the sample. For the samples 6 to 10, the compositions are close to the nominal ones.

By comparing these compositions with the ones depicted in the phase diagram for Ni-Mo, it was possible to establish that the brazing process could be performed in the range of temperature $1350-1450{ }^{\circ} \mathrm{C}$, which is near to the eutectic temperature. The same procedure was used when surfaces of tungsten plates were treated at $1400{ }^{\circ} \mathrm{C}$ for 10 minutes.

The chemical composition determined by EDX, for five tungsten samples, previously coated with binder and heated at $1400{ }^{\circ} \mathrm{C}$ for 5 minutes are presented in Table 2 ; the analyses were performed on $0.5 \mathrm{~cm}^{2}$ and the average standard deviation was $0.06 \mathrm{~mol} \%$.

The best results in terms of homogenization were achieved for temperatures higher than the eutectic temperature, due to the variation of the binder composition applied on the tungsten surfaces, however, after the melting process, the formed alloy began to be homogenous and the composition approached the eutectic one.

The porous tungsten bottom was analyzed by EDX after the decoppering process and the results show that the porous tungsten bottom presents an amount of $0.34 \mathrm{~mol} \%$ of copper, which was reduced after a chemical attack with nitric acid for 10 minutes. After this last procedure, the tungsten bottom presented $0.14 \%$ mol\% of copper, and the concentration of sulfur was $0.14 \mathrm{~mol} \%$.

\subsection{Structural characterization by X-ray diffraction}

XRD analyses were performed on surfaces of alumina plates containing the binder, and in the Ni-Mo alloy obtained after the heating treatment used to melt the binder deposited

Table 1. Binder composition applied on the alumina plate surfaces determined by EDX.

\begin{tabular}{cccccc}
\hline Sample & $\begin{array}{c}\text { Ni } \\
(\mathbf{m o l} \%)\end{array}$ & $\begin{array}{c}\text { Mo } \\
(\mathbf{m o l} \%)\end{array}$ & $\begin{array}{c}\text { Co } \\
(\mathbf{m o l} \%)\end{array}$ & $\begin{array}{c}\text { W } \\
(\mathbf{m o l} \%)\end{array}$ & $\begin{array}{c}\text { Fe } \\
(\mathbf{m o l} \%)\end{array}$ \\
\hline 1 & 72.57 & 27.32 & 0.08 & 0.01 & 0.01 \\
2 & 77.42 & 22.51 & 0.07 & 0.00 & 0.00 \\
3 & 80.51 & 19.40 & 0.09 & 0.00 & 0.00 \\
4 & 71.34 & 28.56 & 0.08 & 0.01 & 0.01 \\
5 & 73.59 & 26.32 & 0.08 & 0.01 & 0.00 \\
6 & 66.77 & 32.54 & 0.07 & 0.01 & 0.01 \\
7 & 66.64 & 33.26 & 0.08 & 0.01 & 0.01 \\
8 & 61.49 & 38.42 & 0.06 & 0.02 & 0.01 \\
9 & 66.07 & 33.82 & 0.09 & 0.01 & 0.01 \\
10 & 60.28 & 39.63 & 0.07 & 0.01 & 0.01 \\
\hline
\end{tabular}

Table 2. The composition of binders applied on the surface of tungsten plates determined by EDX.

\begin{tabular}{cccccc}
\hline Sample & $\begin{array}{c}\text { Ni } \\
(\mathbf{m o l} \%)\end{array}$ & $\begin{array}{c}\text { Mo } \\
(\mathbf{m o l} \%)\end{array}$ & $\begin{array}{c}\text { Co } \\
(\mathbf{m o l} \%)\end{array}$ & $\begin{array}{c}\text { W } \\
(\mathbf{m o l} \%)\end{array}$ & $\begin{array}{c}\text { Fe } \\
(\mathbf{m o l} \%)\end{array}$ \\
\hline 1 & 62.70 & 37.22 & 0.06 & 0.01 & 0.01 \\
2 & 61.78 & 38.13 & 0.07 & 0.01 & 0.01 \\
3 & 63.85 & 36.08 & 0.06 & 0.01 & 0.00 \\
\hline
\end{tabular}


on tungsten plates. In Figure 5a it is noticed that the XRD pattern presents some peaks related to $\mathrm{Ni}$ and Mo crystalline phases in metallic state, typical of each powder. Moreover, in Figure 5b, it is noticed that the XRD pattern for the Ni-Mo alloy presents peaks related to $\mathrm{MoNi}_{4}$ crystalline phase ${ }^{11}$, typical of the Ni-Mo alloys, peaks related to Ni crystalline phase and peaks related to $\mathrm{MoC}_{2}$ crystalline phase ${ }^{12,13}$. This last phase is predominantly superficial and its amount was decrease after cleaning the sample surface.

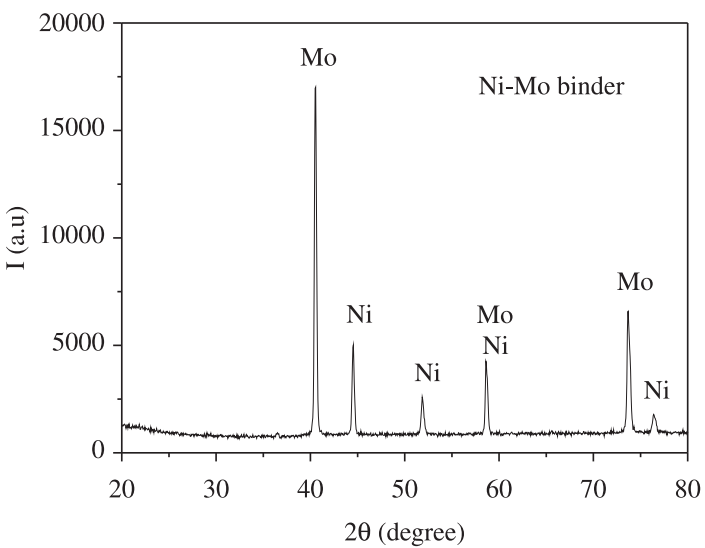

(a)

\subsection{Microstructural characterization}

SEM micrographs of the original powders (Ni or Mo) and after mechanical milling in anhydrous ethanol for 48 hours are shown in Figure 6. The average particle size for $\mathrm{Ni}$ and Mo was determined by laser diffraction and the values are $17.8 \mu \mathrm{m}$ and $37.7 \mu \mathrm{m}$, respectively, and the standard deviation for these data is $0.5 \mu \mathrm{m}$. These results are in agreement with the particles size observed in the scanning

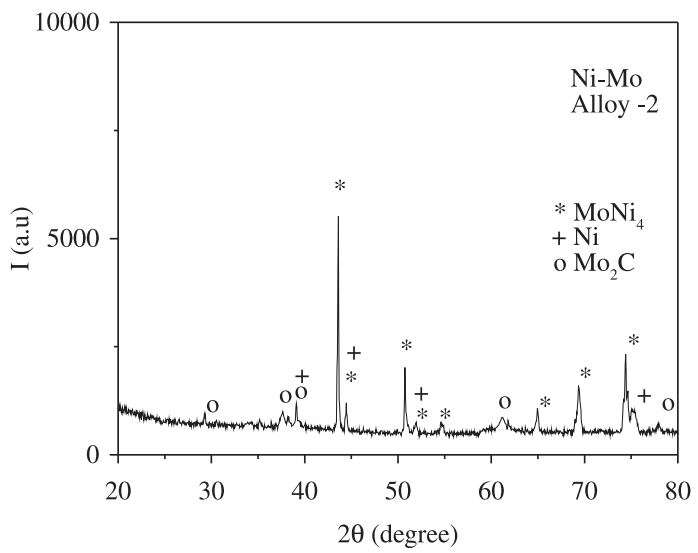

(b)

Figure 5. XRD pattern for a) alumina plate coated by N-Mo binder and b) tungsten sample coated by the Ni-Mo alloy, obtained at $1400{ }^{\circ} \mathrm{C}$.

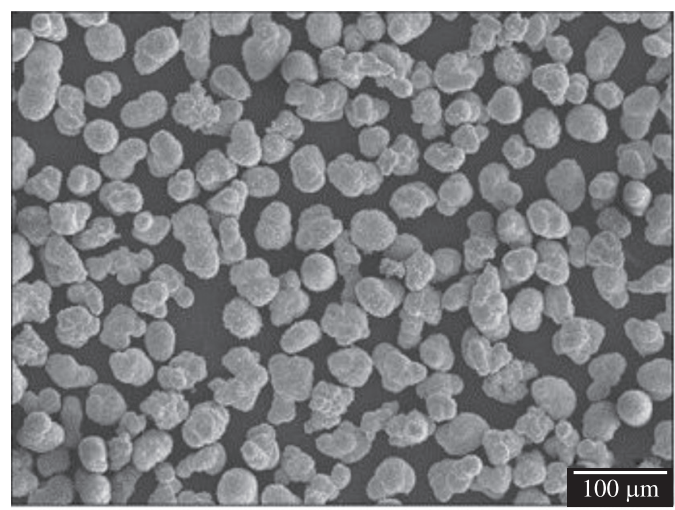

(a)

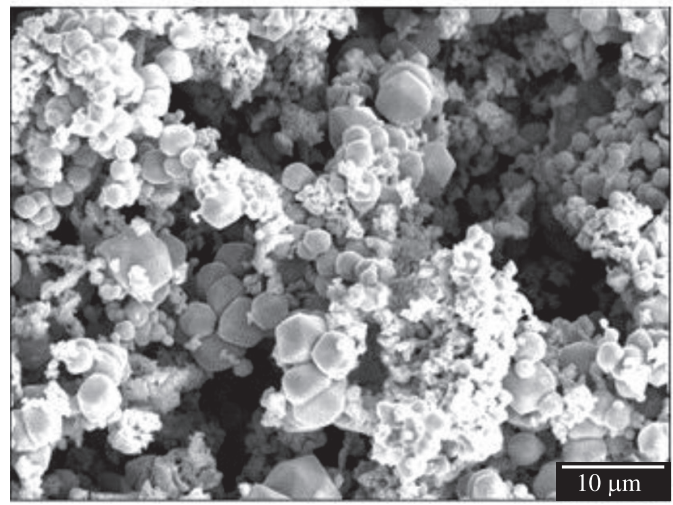

(c)

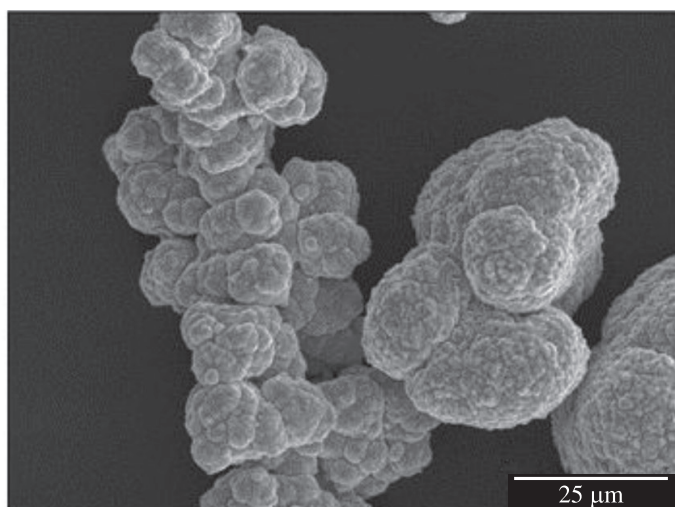

(b)

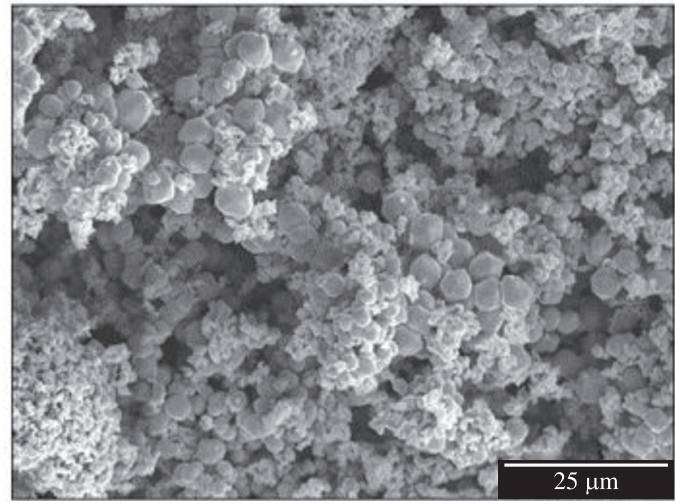

(d)

Figure 6. Scanning electron micrographs obtained for Ni powder (a and b) and Mo (c), before the homogenization and milling process. Micrograph obtained for $\mathrm{Ni}$ and Mo after the homogenization and milling process (d). 


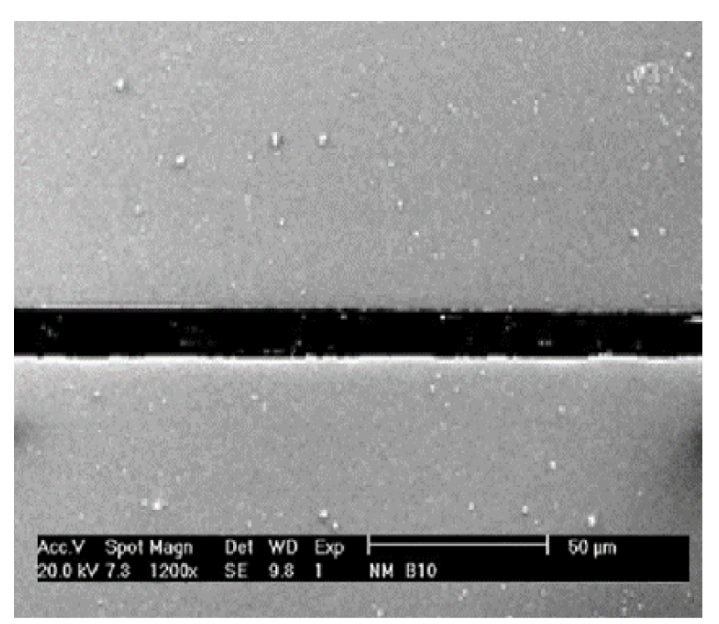

(a)

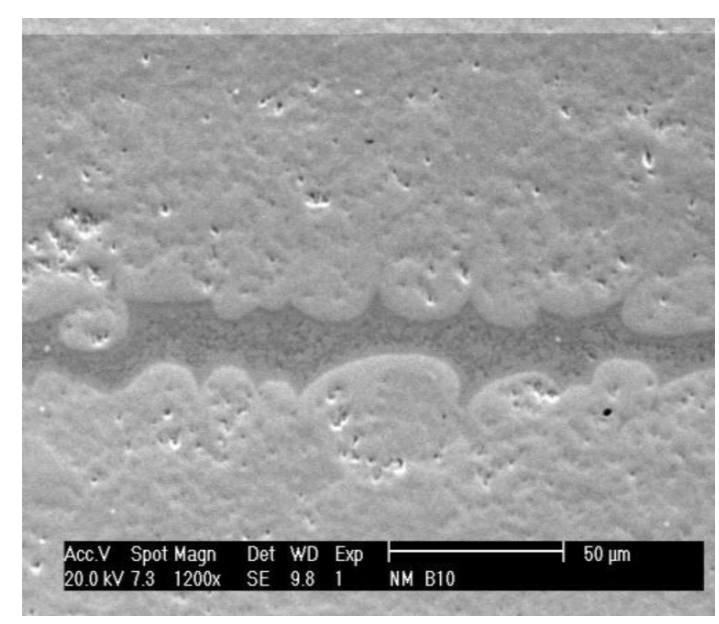

(b)

Figure 7. Scanning electron micrographs for brazing interface between the molybdenum surfaces heated for 10 minutes at: a) $1320{ }^{\circ} \mathrm{C}$ and b) $1400{ }^{\circ} \mathrm{C}$.

electron micrographs, and the particle size is considered suitable to obtain Ni-Mo alloy by melting ${ }^{14}$.

The micrographs in Figure 7 a show the interface where the brazing occurred at $1320{ }^{\circ} \mathrm{C}$ and $1400{ }^{\circ} \mathrm{C}$, respectively. It can be observed that heating at $1320{ }^{\circ} \mathrm{C}$ is not appropriate to braze Mo parts because at this temperature the original powder from the binder do not melt, and consequently wetting and the capillary action do not take place. The same behavior was observed at $1350^{\circ} \mathrm{C}$. however, it can be noticed in Figure $7 \mathrm{~b}$, that the brazing process at $1400{ }^{\circ} \mathrm{C}$ for 10 minutes, was suitable to melt the filler material (Ni-Mo alloy), to wet the surfaces of the components, and consequently to obtain an efficient bonding ${ }^{15}$.

Figure 8 presents the micrograph obtained by SEM for a sample brazed at $1400{ }^{\circ} \mathrm{C}$ for 10 minutes. The chemical composition for the numbered spots (1 to 9) was determined by EDS coupled to the SEM, and Tables 3 and 4 present the amount of $\mathrm{Ni}$ and Mo for each analyzed spot across and along to the brazing interface, respectively; the average standard deviation is $0.05 \mathrm{wt}$. (\%). Figure 9 is the plot of the amount of $\mathrm{Ni}$ as a function of the distance perpendicular of the brazing interface. The center of that interface was chosen as the axis starting point to determine the concentration of $\mathrm{Ni}$. It was observed that the higher amount of $\mathrm{Ni}$ is in the central region of the interface and decreases as a function of the modulus of the distance $\mathrm{x}$, which is an evidence of the nickel diffusion into the bulk of the brazed components.

Figure 10 presents the micrograph obtained by SEM for the porous tungsten and molybdenum brazed at $1400{ }^{\circ} \mathrm{C}$ for 5 minutes, where (a) is the Mo phase, (b) Ni-Mo alloy, and (c) the porous tungsten. From Figure 10 it can be noticed that the brazing process done at $1400{ }^{\circ} \mathrm{C}$ for 5 minutes was suitable to melt the filler material (Ni-Mo alloy), to wet the surfaces of porous tungsten and molybdenum, and consequently to obtain an efficient bonding free of relevant structural damages and defects ${ }^{16}$.

The chemical composition for the numbered spots from 1 to 8 (Figure 11) was determined by EDS coupled to the SEM. Table 5 presents the amount of $\mathrm{Ni}, \mathrm{Mo}$, and $\mathrm{W}$ for

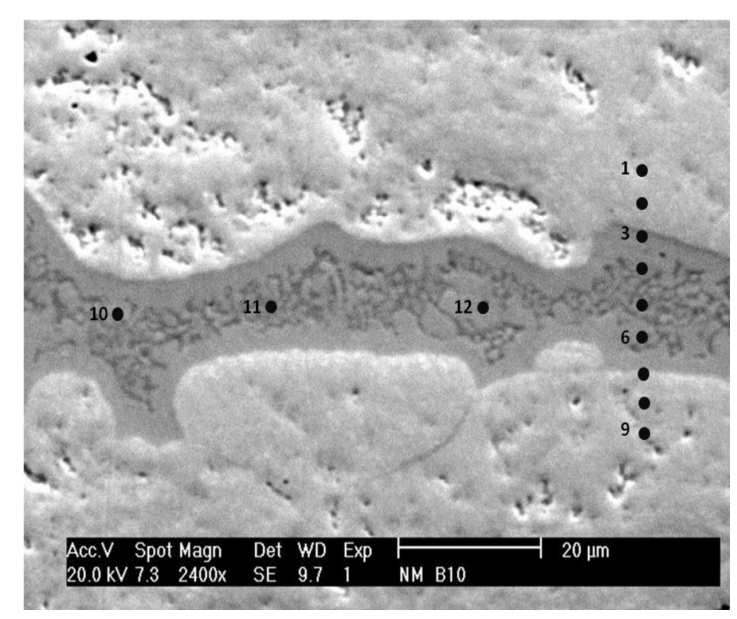

Figure 8. Scanning electron micrograph for the chosen region, used to determine the composition across the brazing.

Table 3. Surface composition for each analyzed sample spot.

\begin{tabular}{ccc}
\hline Spot number & Ni (wt. $(\%))$ & Mo (wt. $(\%))$ \\
\hline 1 & 0.39 & 99.61 \\
2 & 5.57 & 94.43 \\
3 & 24.06 & 75.94 \\
4 & 47.06 & 42.94 \\
5 & 46.81 & 43.19 \\
6 & 37.71 & 62.29 \\
7 & 12.15 & 87.85 \\
8 & 0.55 & 99.45 \\
9 & 0.60 & 99.40 \\
\hline
\end{tabular}

Table 4. Surface composition of the sample for the brazing region.

\begin{tabular}{ccc}
\hline Spot number & Ni (wt. (\%)) & Mo (wt. (\%)) \\
\hline 10 & 48.53 & 51.47 \\
11 & 48.65 & 51.35 \\
12 & 46.81 & 53.19 \\
6 & 47.81 & 52.19 \\
\hline
\end{tabular}


each analyzed spot across the interface, respectively; the average standard deviation is $0.05 \mathrm{wt}$. (\%). Figure 12 shows the amount of $\mathrm{Ni}$ as a function of the distance perpendicular to the interface. It was observed that the higher amount of $\mathrm{Ni}$ is found in the central region of the interface and it decreases as it gets far from the central position (center of the interface) which is an evidence of the nickel diffusion into the bulk of the brazing components. The nickel diffusion is higher into the Mo component than into the W.

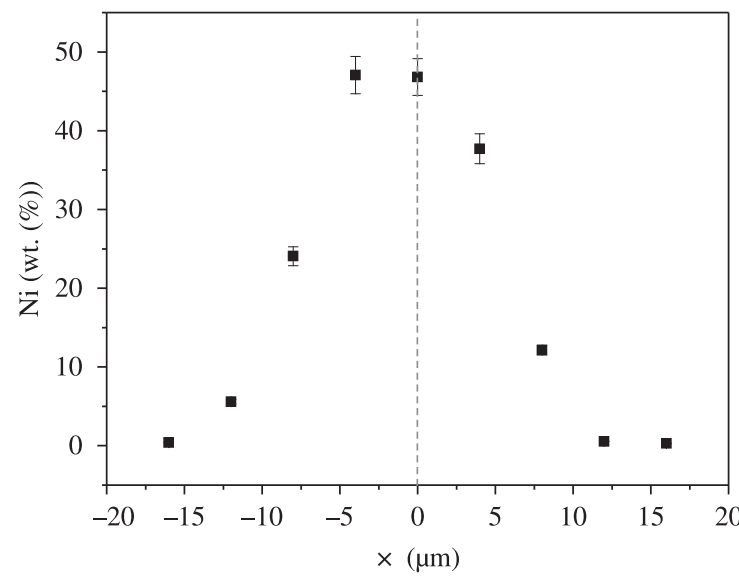

Figure 9. Amount of $\mathrm{Ni}$ as a functio of the distance $\times$, prependicular to the brazing plane.

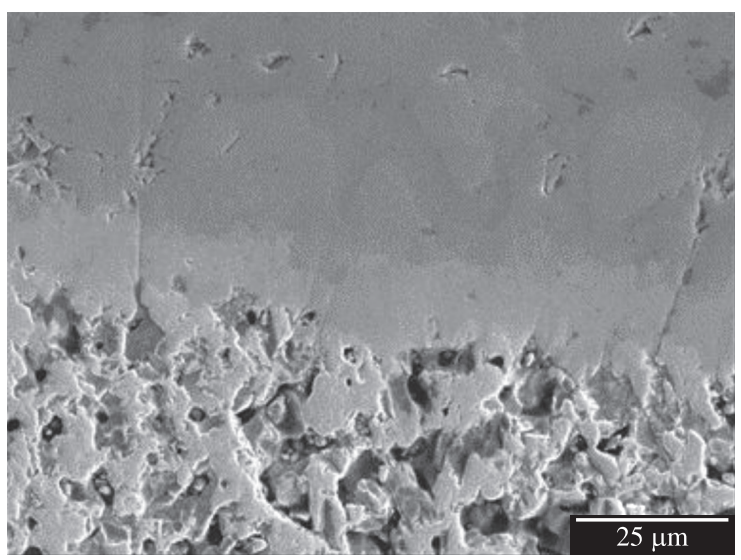

Figure 10. Micrograph for brazing interface between porous tungsten and molybdenum obtained at $1440{ }^{\circ} \mathrm{C}$ for 5 minutes.

Table 5. Sample composition across the brazing interface.

\begin{tabular}{cccc}
\hline Spot number & Ni (wt. (\%)) & Mo (wt. (\%)) & W (wt. (\%)) \\
\hline 1 & 0.29 & 0.18 & 99.52 \\
2 & 3.09 & 2.92 & 93.99 \\
3 & 24.06 & 28.48 & 47.46 \\
4 & 46.06 & 42.92 & 11.02 \\
5 & 47.81 & 44.19 & 8.00 \\
6 & 32.71 & 66.63 & 0.96 \\
7 & 12.15 & 87.47 & 0.38 \\
8 & 0.95 & 98.45 & 0.60 \\
\hline
\end{tabular}

Figure 13 presents a micrograph obtained by SEM for the porous tungsten bottom surface after the decopperization process for 20 hours and a nitric acid attack for 10 minutes. From Figure 13 it is noticed the presence of porous (a) and rounded grain boundaries, which probably occurred due to the chemical attack. These results confirm that the material

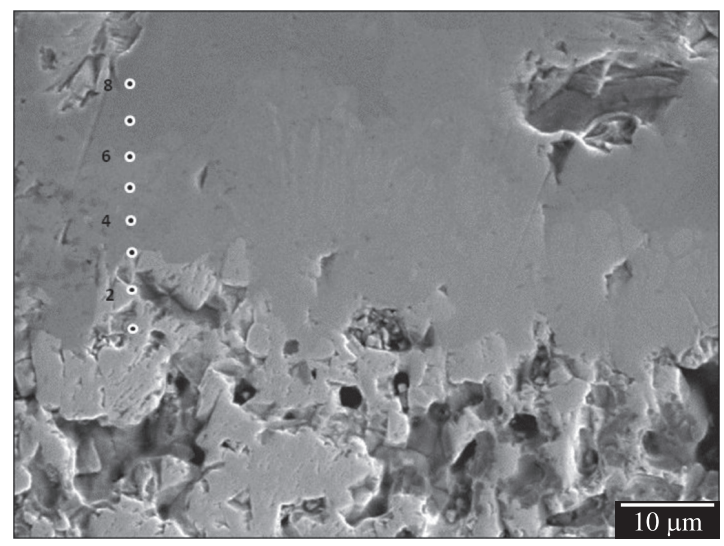

Figure 11. Scanning electron micrograph for chosen region for the study of the brazing between porous tungsten and molybdenum.

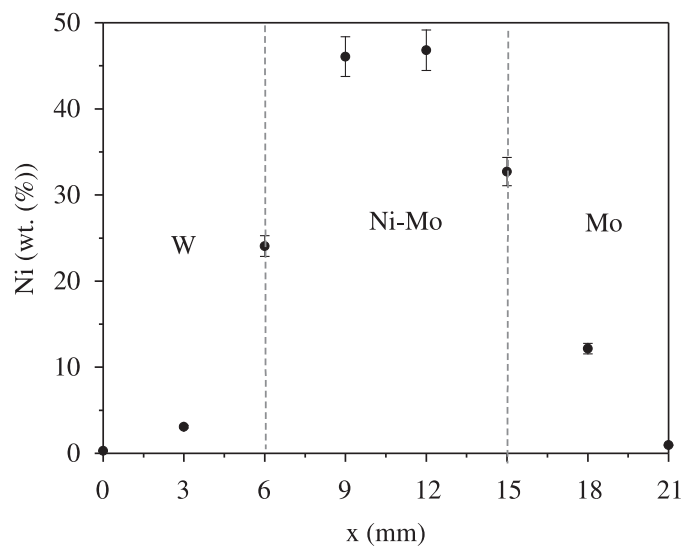

Figure 12. Amount of $\mathrm{Ni}$ as a function of the perpendicular brazing plane.

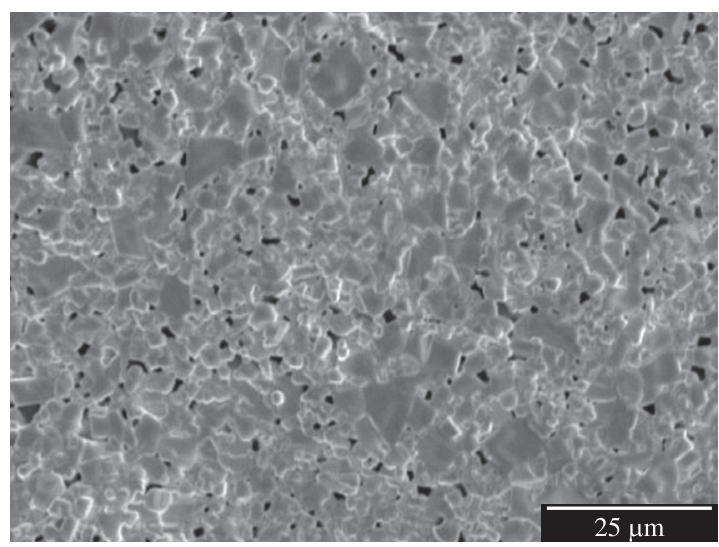

Figure 13. Scanning electron micrograph for the porous tungsten bottom surface after the decopperization followed by the chemical attach. 
obtained by decopperization presents open porosity and the sintering process was reduced. The relative density determined by the Archimedes' method was $77 \%$ of the theoretical value, and it is in agreement to the results obtained by SEM, and consequently confirms that this material is appropriate to the impregnation of aluminates for reservoir cathodes ${ }^{17}$.

\subsection{Mechanical strength tests}

The stress versus strain was plotted for three samples, and the tensile strength average value was $87.9 \pm 0.5 \mathrm{MPa}$, but, in spite of being lower than typical values for metals, allows us to infer that the brazing process is appropriate to join these components, where the stress work condition is lower than the tensile strength for the tested sample.

\section{Conclusions}

Brazing of porous W and dense Mo parts was achieved by using a Ni-Mo eutectic alloy as a filler heated at $1400^{\circ} \mathrm{C}$ for 5 minutes in an induction furnace. The quality of the brazing was confirmed by the presence of a "meniscus" formed by the Ni-Mo alloy on the border of the tungsten

\section{References}

1. Shroff AM. Review of dispenser cathode. Revue Technique Thonson-CSF. 1991; 23:958-965.

2. Schwartz M. Brazing. 5th ed. London: Chapman \& Hall; 1995. p. 91-93.

3. Roberts P. Industrial brazing practice. 5th ed. London: CRC Press; 2004. p. 11-18.

4. Raju SR. Impregnated cathodes for use in high power microwave tubes. [Thesis]. Cambridge: Cambridge University; 1987.

5. Karolus M, Niedbata J, Rowinski E, Lajiewika E and Budniok A. Preparation and structure of the electrodeposited Ni-Mo alloys with polymers. Jounal of Achievements in Materials and Manufacturing Engineering. 2006; 16(1-2):25-29.

6. Dinesh C. Chronology of Developments in Ni-Mo Alloys: The Last 70 Years. Denver; Corrosion; 2002.

7. Arya A, Banerjee S, Das GP, Dasgupta I, Saha-Dasgupta $\mathrm{T}$ and Mookerjee A. A first principles thermodynamic approach to ordering in Ni-Mo alloys. Acta Materialia. 2001; 49(17):3575-87. http://dx.doi.org/10.1016/ S1359-6454(01)00235-X

8. Costa FA, Silva AGP, Ambrozio FF and Gomes UU. Solid state sintering of a w-25w\% Ag powder prepared by high energy milling. International Journal of Refractory Metals \& Hard Materials. 2008; 26:318-323.

9. Soares EP, Perigo EA, Takiishi H, Motta CC and Faria RN. A study of Pr-Fe-B magnets produced by a low-cost powder method and the hydrogen decrepitation process. Materials and molybdenum joint, and by the features of the interface between the tungsten and molybdenum alloys observed by scanning electron microscopy.

The temperature for the brazing process is $90{ }^{\circ} \mathrm{C}$ above the eutectic temperature to assure the melting of the filler material, since there generally has a variation of the binder composition when deposited on the tungsten and molybdenum surfaces. However, after the melting process, the alloy was homogenized and presented compositions close to the eutectic ones.

We concluded that the brazing process performed by inductive heating using Ni-Mo alloy as a filler material in dry hydrogen atmosphere is appropriate to join porous tungsten cathode and dense molybdenum cathode parts for microwaves tubes manufacture.

\section{Acknowledgements}

The authors acknowledge FINEP (contract number 01.09.0049.01) and CNPq (process number 308641/2008-6) for the financial support. The authors are indebted to Dr. R. Muccillo (Fapesp Project \# 96-9604/9) for the XRD, and Dr. J.R. Martinelli for helping with the manuscript.

Research. 2005; 8(2):143-145. http://dx.doi.org/10.1590/ S1516-14392005000200008

10. Richardson N. Combined Auger and emission microscopy of impregnated cathodes. [Thesis]. Cambridge: Clare College; 1980.

11. Carturan G, Cocco G, Enzo S, Ganzerla R and Lenarda M. Hexagonal close packed nickel powder: Synthesis, structural characterization and thermal behavior. Materials Letters. 1988; 7(1-2):48-53. http://dx.doi.org/10.1016/0167577X(88)90080-8

12. Swanson T. Standard X-ray diffraction powder patterns. National Bureau of Standards Circular. 1953; 539(1):20.

13. Velikanova T, Kublii V and Khaenko B. Solid state transformation and phase equilibria in the molybdenumcarbon system. Soviet Powder Metallurgy and Metal Ceramics. 1988; 27:891.

14. German RM. Powder metallurgy science. Princeton: Metal Powder Industries; 1994.

15. Harfer J. The Crystal Structure of $\mathrm{Ni}_{4}$ Mo. Journal of Chemical Physics. 1944; 12(7):315-8. http://dx.doi. org/10.1063/1.1723945

16. Cao J, He P and Wang M. Mechanical milling of Ti-Ni-Si filler metal for brazing TiAl intermetallics. Intermetallics. $2011 ; 19(7): 855-859$. http://dx.doi. org/10.1016/j.intermet.2011.01.017

17. Gonçalves JAN. Estudo e desenvolvimento de catodos óxidos ( $\mathrm{Ba}, \mathrm{Sr}, \mathrm{Ca}) \mathrm{O}$ em configurações cilíndricas. [Dissertation]. São José dos Campos: Instituto Tecnológico da Aeronáutica; 1996. 